\title{
Integrated mosquito management in rice field in China
}

\author{
Tong-Yan Zhao $\bullet$ Rui-De Xue
}

Received: 27 February 2021 / Accepted: 5 October 2021 / Published online: 23 October 2021

(C) The Author(s) 2021

\begin{abstract}
Rice cultivation is important in China with over 29.33 million $\mathrm{hm}^{2}$ of rice fields, producing $28.9 \%$ of rice yields worldwide. Rice fields are mass breeding sites for mosquitoes with approximately 40 mosquito species found breeding amongst them. Anopheles sinensis, Anopheles lesteri, and Culex tritaeniorhynchus are the three main species that are found breeding in rice fields. An. sinensis and An. lesteri are important vectors of malaria in flat areas of China, and Cx. tritaeniorhynchus is a main vector of Japanese B encephalitis. This review provides the principles of mosquito control used to target the species of mosquitoes breeding in rice fields, as well as some main approaches that have been tested and implemented for mosquito control in the past 70 years. The irrigation management of rice fields is included, such as intermittent irrigation, wet irrigation, controlled irrigation, and rotation of rice fields and dry fields. Biocontrol measures and agents, including rice-fish coculture, Azolla, Bacillus thuringiensis israelensis (Bti), and Bacillus sphaericus, for mosquito control
\end{abstract}

T.-Y. Zhao ( $₫)$

State Key Laboratory of Pathogen and Biosecurity, Beijing Institute of Microbiology and Epidemiology, Beijing 100071, China e-mail: tongyanzhao@126.com

R.-D. Xue ( $\bowtie)$

Anastasia Mosquito Control District, St. Augustine, FL 32092, USA

e-mail: xueamcd@gmail.com are discussed. These control methods benefit the prevention and control of mosquito-borne disease, especially malaria elimination in China.

Keywords Rice field · Mosquito control · Wetting irritation · Rice-fish coculture

\section{Rice field distribution and breeding species of mosquito in China}

Rice cultivation is important in Chinese agriculture. There are 29.33 million $\mathrm{hm}^{2}$ of rice fields in China, which produce $23-30 \%$ of rice yields in the world (Zhang et al. 2018). Rice fields are distributed into six zones, including the double cropping rice zone in south China, the double or single rice cropping zones in central and southwest China, and the single cropping zone in north China. There is also an early maturing single cropping rice zone in northeast China and a single cropping rice zone of dry area in northwest China. Rice fields are huge breeding sites for mosquito larvae with more than 40 species of mosquitoes found amongst them due to standing water in rice fields, Anopheles sinensis Wiedemann 1828, An. lesteri Baisas et $\mathrm{Hu}, 1936$, and Culex tritaeniorhynchus Giles 1901 are the main species in rice fields. The two species of Anopheles mosquitoes are important vectors of malaria and filariasis, and $C x$. 
tritaeniorhynchus is the main vector of Japanese B encephalitis in China (Lu 1999).

Anopheles sinensis is distributed throughout all parts of China that are south of $45^{\circ}$ north latitude and east of $90^{\circ}$ east longitude, except for Qinghai and Xinjiang ( $\mathrm{Lu} \mathrm{1997b).} \mathrm{This} \mathrm{species} \mathrm{mainly} \mathrm{breeds} \mathrm{in}$ rice fields. But may also breed in standing water of reed ponds, lotus ponds, and water bamboo fields, which are all typical breeding sites of field and pond breeding mosquito species. Seasonal fluctuations of this species depend on cultivation of rice fields, standing water present, and temperature zones. The peak of density of An. sinensis has double peaks during June through August in the double cropping rice zone, and only one peak in the single cropping rice zone. Anopheles sinensis is zoophagic and exophagic at dusk, especially preferring to feed on cow blood, and is endophilic in cowsheds (Lu 1999).

Anopheles lesteri is a sibling species of An. sinensis, which belongs to the Anopheles hyrcanus complex. The species was named as An. anthrophagus $\mathrm{Xu}$ et Feng, 1975 which is considered as synonym of An. lesteri (Harbach 2004; Qu 2005, 2008; Rueda et al. 2005). This species is distributed throughout all areas south of $34^{\circ}$ north latitude of China. Anopheles lesteri breeds in rice fields that use spring water for irrigation, and disperses around shelter near the rice field, which is anthropophagic (anthropophilic) and endophilic (Lu 1997b).

Culex tritaeniorhynchus is distributed throughout all parts of China, except for Qinghai and Xinjiang, and is a dominant species in rice field mosquito community (Lu 1997a). Culex tritaeniorhynchus breeds widely in water with floating plants, such as ponds, marshes, puddles, low-lying areas, and feed ditches, occasionally breeding in stone caves and containers. This species breeds in both clean and polluted water. Culex tritaeniorhynchus is zoophagic, especially preferring pigs, and cattle. Culex tritaeniorhynchus is endophagic, entering the cowsheds during the night, and is exophilic after blood meal. Seasonal fluctuation of Cx. tritaeniorhynchus not only depends on geographic zone, but also on rice cultivation, having only one peak density at the single rice cropping zone from July to August, and two density peaks in the double rice cropping zone (Lu 1999).

Other species of mosquitoes that breed in rice fields include Aedes vexans Meigen, 1830, Cx. vagans Wiedemann, 1828, Cx. bitaeniorhynchus Giles,
1901, Cx. fuscocephala Theobald, 1907, Cx. gelidus Theobald, 1901 and Cx. whitmorei Theobald, 1904. While these species are blood-sucking and cause nuisance problems, they are not of medical importance (Lu 1999).

\section{Integrated mosquito management (IMM) in rice field}

The concept and principles of integrated mosquito management was formed in the 1970's based on the practices of mosquito and mosquito-borne disease control in China (Lu 1978). Mosquitoes, environment, social conditions, and principles of both temporary and permanent control solutions were investigated, mainly focusing on permanent solutions grounded on local conditions and time. This formed a systematic management that combined environmental, chemical, biological, and physical control methods with emphasis on harmful species of mosquitoes. Management aimed to reduce vector mosquito densities under a threshold level that mitigated risk, eliminated mosquitoes under certain conditions, and finally eradicated the pests and diseases carried by mosquitoes. The principles of IMM contains four key points. The first point addresses the uniformity of mosquitoes, environment, and control measures, due to the link between breeding and control and nature and social environment. Environmental factors were not only considered as environment control measures, but also within other control measures. Based on the environmental conditions, suitable control methods and tools should be selected and conducted, while simultaneously protect the environment. The second point emphasizes a permanent solution by selecting and implementing environmental management as the major priority. The third point emphasizes targeting harmful species of mosquitoes, particularly vector species of mosquito-borne diseases. The fourth point aims to control the density of mosquito species, as opposed to eradication (Lu 1999).

Anopheles sinensis displays complex behaviors, such as resting half time in homes, preventing a textbook integrated mosquito management (IMM) plan, as described above, for this species of mosquito. The IMM plan for larval An. sinensis has been conducted with wetting irrigation, rotation of rice field and dry field, and fish cultivation in rice field. 
Wetting irrigation is a kind of water-saving and shallow water irrigation plan that allows seedlings to germinate in a flooded field. Once seedling establishment occurs the flooded field was treated with draining and drying. Shallow water irrigation is carried out based on the need of growing rice for 21-26 times without draining after the first irrigation. This method maybe selected based on the soil situation in each zone. Pyrethroid insecticide-impregnated bed-nets (ITN) in human houses and indoor residual spraying (IRS) in cowsheds were also implemented as part of the IMM rice field control in residential communities for adult mosquito control (Lu 1999).

Culex tritaeniorhynchus is difficult to control. Based on breeding habits and other characteristics, the management of larval $C x$. tritaeniorhynchus is the same as the method for control of larval An. sinensis. This includes wetting irrigation and fish cultivation. However, the IRS in hog houses is not a suitable method to control this species due to its exophilic and resting habits. The use of pyrethroid ITN is also not a practical control method of C. tritaeniorhynchus. Alternative methods were selected for control of both species of mosquitoes, including the application of light traps to trap adult mosquitoes inside hog sheds and pig farms since pigs are amplifying hosts for Japanese B encephalitis in China (Lu 1999).

Main applications for control of An. lesteri were IRS and pyrethroid ITN in residential houses because the species is anthropophagic and endophagic, and the larvae breed in rice fields. The methods of wet irrigation, rotation rice field and dry field, and fish cultivation in rice field are suitable to control the species in many areas. The successful control of $A n$. lesteri was achieved during the elimination of malaria in China. Now it is difficult to collect or find this species from the areas where An. lesteri was originally distributed (Lu 1999).

\section{Irrigation system and its impact on mosquito breeding}

Irrigation of rice fields in China accounts for approximately $50 \%$ of total water consumed nationwide. Reduction of water consumption and improvement of irrigation systems are of critical importance and demand due to a shortage of the water supply. There are four major water-saving irrigation technologies used in rice fields, including wet irrigation, intermittent submerged irrigation, controlled irrigation, and rotation of rice field and dry field.

China has implemented and promoted the management of irrigation systems to control mosquitoes for many decades. Documents from the 1950's confirmed that an application experiment with intermittent submerged irrigation in rice field significantly reduced densities of An. sinensis and Cx. tritaeniorhynchus in Shanghai, Sichuan, and Guangdong provinces (Lu 1999). The percent larval reductions of An. sinensis and $C x$. tritaeniorhynchus in wet irrigation fields were $84-86 \%$ and $81-91 \%$, respectively. The applications of these methods increased rice production by $10 \%$ and saved water consumption by 50\% from 1978 to 1979 (Lu 1999). In another practice of intermittent irrigation carried out in Jiangsu province, the densities of An. sinensis and Cx. tritaeniorhynchus were reduced by $79.84 \%$ and $72.14 \%$, respectively, with the average rice yield increasing by $22.5 \mathrm{~kg} / 667 \mathrm{~m}^{2}$, and overall water conservation at $187.4 \mathrm{~m}^{3} / 667 \mathrm{~m}^{2}$ (Cao et al. 2012).

Wet irrigation was similar to intermittent submerged irrigation. Seedlings are allowed to germinate in a flooded field; however, once seedling establishment occurs the flooded field is treated with draining and drying, then control irrigation begins. Wet irrigation is conducted once every five days and results in the absence of standing water in rice fields for mosquitoes to breed in. This process requires 21-26 cycles of irrigation from seedlings to harvest of rice (Lu 1988). There was a field trial of wet irrigation for mosquito control in rice field in Wushe county of Henan province in 1977 (Ge et al. 1978). The dominating species of mosquitoes in the area were Cx. tritaeniorhynchus $(47.6 \%)$ and An. sinensis $(36.1 \%)$. Irrigation was applied every five days in rice fields based on observation of egg hatching of $C x$. tritaeniorhynchus and An. sinensis. The total mosquito larval reduction in the wet irrigation rice field was $85.9 \%$, of which Cx. tritaeniorhynchus and An. sinensis reductions were $89.4 \%$ and $93.1 \%$, respectively, compared to pond rice fields. Mosquito pupae were not found in the wet irrigation rice field during the trial. A large-scale field trial of wet irrigation in rice fields was carried out in Yellow River alluvial plain, located in Henan province, including Wushe, Yuanyang and Huojia counties in 1978 and 1979. The reduction rates of An. sinensis in 1978 and 1979 were 
$81 \%$ and $86 \%$, respectively. The reduction rates of Cx. tritaeniorhynchus in 1978 and 1979 were $91 \%$ and $81 \%$, respectively. Only first and second instar larvae were found and collected from rice fields with wet irrigation in June, early July, and after August. Reduction rates of adult mosquitoes collected near wet irrigated fields in 1978 and 1979 were 53\% and $77 \%$ for An. sinensis and $55 \%$ and $70 \%$ for $C x$. tritaeniorhynchus. The decline rate of malaria cases in villages was $13-32 \%$ in 1978, compared with those in 1977, and the decline of malaria cases in villages was 50-72\% in 1979, compared with those in 1978, indicating that the wet irrigation method reduced the incidence of malaria (Ge et al. 1981).

There was a comparative study of wet irrigation for mosquito control that compared irrigation every five to seven days in Wushe county, Henan province in 1978 (Cooperation group of rice field mosquito control of Wushe county 1979). The document showed that the larval reduction rates of Anopheles and Culex were $89.5 \%$ and $90.2 \%$, respectively, with irrigation every five days, and $91.4 \%$ and $91.7 \%$, respectively, with irrigation every seven days. Most of the larvae were 1st and 2nd instar larvae, with few 3rd and 4th instar larvae collected from the rice field. No pupae were collected.

Aside from these studies on wet irrigation in rice fields for mosquito control in Henan province, similar research and practices were conducted in Jiangsu province (Sun et al. 1988; Sun et al. 1989). Similar results on reduction of mosquito densities and malaria morbidity were also reported.

Based on the development of water conservancy and the source of irrigation water in Sichuan province, the practice of rotation of rice fields and dry fields were conducted. There was no water in rice fields in the winter. The efforts have changed the breeding sites for vector mosquitoes of malaria. The densities of $A n$. sinensis and An. lesteri in human houses declined by $97.63 \%$ and $92.31 \%$, respectively, in comparison to before and after the rotation cultivation in 1982 and 1999. This study also reported that reduction rates of An. sinensis and An. lesteri in human-dwellings were $78.57 \%$ and $64.29 \%$, respectively. The reduction of $A n$. sinensis and An. lesteri population densities in cowsheds were $75.17 \%$ and $80.66 \%$, respectively, in the rotation cultivation area and control area in 1999. Simultaneously, the morbidity of malaria had been continuously declining, even without the application of pyrethroid insecticide-impregnated bed nets in the rotation cultivation area in Sichuan province from 1994 to 1999 (Gao et al. 2000).

An investigation was conducted about the influence of the rotation cultivation on densities and morbidity of malaria in, Shibantan, Chengdu. The rotation of cultivation of rice fields and dry fields has been applied gradually after three reservoirs were constructed in 1978 (Liu et al. 2003). The reduction rates of An. lesteri and An. sinensis were $100 \%$ and $92.86 \%$, respectively, in the human houses, and $100 \%$ and $82.14 \%$, respectively, in cowsheds, compared with the reduction rates in 1982 and 2000 . The morbidity of malaria has declined since 1978 . There were no cases of malaria from 1988 to 2002 in the area. This indicated that the elimination of rice field flooding over the winter could reduce the densities of Anopheles and morbidity of malaria.

There was an investigation about the relationship between rotation cultivation of rice fields and dry fields and densities and malaria (Gao et al. 2000; Liu et al. 2002a, b). The rotation of rice fields and dry fields has been carried out in Sichuan province. The single cropping rice field with water storage in winter has been changed into double or triple cropping fields with rice, wheat, and rapeseed rotations. The duration of complete absence of water in the dry field was up to 267 days. The breeding habitat for Anopheles was lost, resulting in the decrease and local elimination of $A n$. lesteri and An. sinensis. This impacted the malaria epidemic. There was a negative correlation between the rate of rotation of rice fields and dry fields and morbidity of malaria. The decrease in flooding of rice fields and the increase in the rotation of cultivation resulted in the decline in morbidity of malaria (Table 1) (Liu et al. 2002c). Interestingly, intercropping of cotton and rice also reduced the densities of Anopheles in areas where cotton fields were near villages in Jiangsu province (Lu 1999).

A comparative observation was done on the influence of irrigation systems for An. lesteri densities in Fujian province (Xu et al. 2002). Basin irrigation had been applied in Jiangle county every year, the rotation flow of irrigation and drainage had been carried out in Shaowu county, and there was no standing water in rice field. Both locations were single cropping areas and the distance between the two locations was $200 \mathrm{~km}$. The density of An. lesteri was 16.9 bites per human per night in Jiangle and 0.9 bites per human per 
Table 1 The morbidity of malaria and rotation cultivation of rice field and dry field in Sichuan province, China

\begin{tabular}{llll}
\hline year & Area of flood paddy field (10 thousand ha.) & Rotation cultivation rate $(\%)$ & morbidity of malaria \\
\hline $1950 \mathrm{~s}$ & 200 & 60 & $60-80 /$ per 10 thousandth \\
$1960 \mathrm{~s}$ & $150-200$ & $40-60$ & $15-50 /$ per 10 thousandth \\
$1970-1980 \mathrm{~s}$ & 100 & 30 & $10 /$ per 10 thousandth \\
$1990-2000$ & $50-70$ & $20-30$ & $1 /$ per 10 thousandth \\
\hline
\end{tabular}

night in Shaowu. Two peaks in population density of An. lesteri occurred in June through July and September in Jiangle. Only one population peak occurred in June through July in Shaowu. This indicated that the irrigation system influenced the breeding and seasonal abundance of An. lesteri in rice fields.

Some practices of controlled irrigation involving the placement of dryland rice under plastic mulch film and semiarid cropping systems were carried out in rice fields in China. These practices were related to mosquito control in rice fields (Chen et al. 2012). The thin water layer was kept in rice field at seedling transplant time in the same field during controlled irrigation. There was a water-free layer in rice fields during every stage of rice growth after seedling planting, which determined the time and the amount of water of controlled irrigation based on soil water content. There was no standing water in the field and the breeding of mosquitoes had been limited. The controlled irrigation could benefit the yield of rice and act as a water saving approach. This practice has become a widely used and popular application in China. The dryland rice under plastic film mulch and semiarid cropping system occasionally resulted in no standing water present in rice field. This benefitted the control of mosquito breeding in rice field. The method has been used in China since the 1990's ( $\mathrm{Li}$ et al. 2005).

\section{Fish cultivation in rice fields and its impact on mosquito breeding}

Fish cultivation in Chinese rice fields began around 220-280 BC. Rice-fish coculture in rice fields facilitates the growth of rice and benefits the rice yield, which is favorable to farmers due to the harvest of rice and fish simultaneously. Rice-fish coculture in the Long-Xiang village of Qingtian county in Zhejiang province was selected as the first list of the Globally Important Agricultural Heritage System (GIAHS) in 2005 (Ren et al. 2018). The ecological legacy of these traditional agricultural systems and the integration of these unique experiences have been recognized and adopted into future farm development and sustainable agriculture (Hu et al. 2016; Ren et al. 2018; Xie et al. 2011). Meanwhile, the rice-fish coculture benefitted the control of mosquito breeding in rice fields, and blocked the transmission of mosquito-borne diseases, including malaria and Japanese B encephalitis in China ( $\mathrm{Lu} \mathrm{1999).} \mathrm{There} \mathrm{were} \mathrm{five} \mathrm{periods} \mathrm{in} \mathrm{the}$ development of the rice-fish coculture. The first period was the 1950's, which was called the recovery and development of traditional fish culture. In 1959 the area of fish culture had grown up to 670,000 ha in China, but wide application of insecticides conflicted with fish coculture in rice fields, and fish culture declined during this period. The second period was the innovation and perfection of theory and technology in the fish culture from the 1980's to the 1990's. The ricefish commensalism system was formed based on the theory that fish benefited the rice, and that the relationship between fish and rice was symbiotic $(\mathrm{Ni}$ and Wang 1981). The infrastructure, production style, and production technology were developed. The species of fish including of carp (Cyprinus carpio), grass carp (Ctenopharyngodon idella), silver carp (Hypophthalmichthys molitrix), bighead carp (Hypophthalmichthys nobilis), gibel carp (Carassius auratus), Mozambique tilapia (Oreochromis mossambicus), and moustache catfish (Clarias lazera) had become the common species of fish cultivated in rice fields. In 1982, there were only 11 provinces with 340,000 ha where fish and rice were co-cultivated by 1994, that area had grown to 850,000 ha across 24 provinces. Fish cultivation in rice fields was adopted as one of the major approaches for mosquito control in the IMM plan developed by the Patriotic Health 
Commission National committee in 1983. The third period was from the 1990's to the 2000's. It involved a rapid development of fish cultivation. The area of fish cultivation in rice fields reached $1,650,000$ ha across 25 provinces, and about $6,000,000$ ha of rice fields became eligible for fish culture. The fourth period was from 2000 to 2011. The period was called the transformation and upgrade for fish cultivation, which has been combined with the rice-crab, rice-crayfish, rice-loach, rice-turtle, rice-shrimp, rice-frog, and riceloach field cultivation systems. The fifth period was a rapid development phase that extended from 2011 to present (Anonymous 2020; Huang and Zong 2007; Li et al. 2019; Tang et al. 2020). The implementation of fish cultivation in rice fields reduced density of larval Anopheles mosquitoes by $80 \%$ when compared to those in rice fields without fish in field trials in several provinces (Lu 1999).

Several field trials and practices have been conducted in different provinces at different times. There was an observation of mosquito control of rice-fish coculture on single cropping rice fields and double cropping rice fields in Wuxing county, Zhejiang province, Southeastern China in 1958 (Chen and Gao 1959). The reduction rates of Anopheles and Culex were $88.95 \%$ and $99.5 \%$, respectively, in double cropping rice fields including small sized carps (C. carpio, body length $3.0-3.5 \mathrm{~cm}$ ), compared to the densities of larval mosquitoes in rice fields without fishes. The reduction rates of Anopheles and Culex were $79.9 \%$ and $99.5 \%$, respectively, in double cropping rice fields including large sized carps $(C$. carpio, body length $9.0-11.5 \mathrm{~cm}$ ), compared to the densities of larval mosquitoes in rice fields without fishes. The reduction rates of Anopheles and Culex were $72.2 \%$ and $95.5 \%$, respectively, in single cropping rice fields including small sized carps (body length 3.0-3.5 cm), compared to the densities of larval mosquitoes in rice fields without fishes. The rice production also increased by $8 \%$ and $20 \%$, respectively, in double cropping rice fields including small sized carps (body length $3.0-3.5 \mathrm{~cm}$ ) and large sized carps (body length 9.0-11.5).

There were trials of rice-fish coculture for mosquito control for two consecutive years in Nanyang county and Luyi county of Henan province in 1972, 1973 and 1974 (Malaria control trail working group of Nanyang county 1975; Malaria control trail working group of Henan province, Zhoukou district and Luyi county in Guantang community 1973, Malaria control trail working group of Henan province, Zhoukou district and Luyi county in Guantang community 1974a). Carps, with body lengths of $1.7-5.0 \mathrm{~cm}$ were placed in rice fields at a density of 6000 fishes/0.74 ha. This resulted in reduction rates of Anopheles and Culex by $78.3 \%$ and $96.4 \%$, respectively, compared to the control field without fishes in Nanyang county.

The field trial in Hunan province resulted in a decline of larval and adult mosquito densities ( $\mathrm{Li}$ et al. 1986). Three fish species were introduced into rice fields, including carp, grass carp, and gibel carp. Carps, with body lengths of $3.3-4.9 \mathrm{~cm}$ at a density of 600 fishes/Mu (0.067 ha) in May and June. The reduction rates of all species of mosquito larvae were $76 \%$ and $70.4 \%$, respectively, in July and August. All adult mosquito species populations were reduced by $76.8 \%$ around rice fields in August.

A field trail in Hubei province indicated that the reduction rates of densities of larval An. sinensis and Cx. tritaeniorhynchus were $87.9 \%$ and $80 \%$, respectively, after putting grass carps into the rice field at a density of $1.9 \mathrm{fish} / \mathrm{m}^{2}$ after 78 days (Liao et al. 1991).

There was a report about the field research on the rice-fish coculture and the decline of malaria in Chengdu city of Sichuan province. Carps and grass carps with body lengths of $3.0-4.0 \mathrm{~cm}$ were introduced in rice fields at 300 fishes/Mu (0.067 hectare). The reduction rate of total mosquito larvae was about $80 \%$ and the decline of malaria cases was $82.4 \%$ in 1984 (Wu 1984). The densities of larval and adult mosquitoes, including An. sinensis and Cx. tritaeniorhynchus, in the rice-fish coculture area declined to below $80 \%$ in Quanzhou county of Guangxi province (Wu 1984) after the application of rice on the ridge and fish in the furrow. This was an innovation in the ricefish coculture system.

Wide applications of wet irrigation in rice field area of Yellow River alluvial plain and the promotion of the IMM, mainly through the application of fish cultivation in ponds and puddles nearby villages and rice fields, were carried out in Henan province (Ge et al. 1985). The efforts reduced 73.3-94.8\% and $59.4-94.7 \%$ of the total mosquito populations based on sampling of man-bait net and cow-bait net, respectively, in different experimental areas by year (Table 2). The applications of fish cultivation were carried out to ponds and puddles of $490 \mathrm{~m}^{2}$ with 5000 carps in the first area and to $99,000 \mathrm{~m}^{2}$ ponds and 
Table 2 The densities of mosquito in experiment and control area based integrated control of mosquitoes practice in paddle areas on the alluvial plain of the Yellow River

\begin{tabular}{llllllll}
\hline $\begin{array}{l}\text { Experiment } \\
\text { zone }\end{array}$ & Year & $\begin{array}{l}\text { Man-bait net in } \\
\text { experiment area* }\end{array}$ & $\begin{array}{l}\text { Man-bait net in } \\
\text { control area }\end{array}$ & $\begin{array}{l}\text { Reduction } \\
\text { rate }\end{array}$ & $\begin{array}{l}\text { Cow-bait net in } \\
\text { experiment area }\end{array}$ & $\begin{array}{l}\text { Cow-bait net in } \\
\text { control area }\end{array}$ & $\begin{array}{l}\text { Reduction } \\
\text { rate }\end{array}$ \\
\hline A & 1981 & 10.6 & 147.3 & 92.9 & 56.6 & 1052 & 94.7 \\
& 1982 & 14.3 & 271.7 & 94.8 & 225.6 & 816.2 & 72.4 \\
B & 1979 & 41.0 & 165.5 & 75.3 & 441.7 & 1087.5 & 59.4 \\
& 1982 & 72.8 & 271.7 & 73.3 & 213.1 & 827.8 & 74.3 \\
\hline
\end{tabular}

*Individuals/net, h

puddles with 220,000 carps, grass carps, and silver carps in the second area. The reduction rates of $A n$. sinensis in human houses were $53.2 \%$ and $97.9 \%$ in 1981 and in 1982, respectively, in the first area, and $66.7 \%$ and $76.8 \%$ in 1979 and 1982, respectively, in the second area. The reduction rates of $C x$. tritaeniorhynchus were $93.8 \%$ and $94.2 \%$ in the first area in 1981 and 1982, respectively, and $87.2 \%$ and $70.8 \%$ in 1979 and 1982, respectively, in the second area. The reduction rates of $A n$. sinensis and $C x$. tritaeniorhynchus in the cowsheds were similar with those in human houses. The larval density reductions in rice fields were $91.2 \%$ and $95.1 \%$ in 1981 and 1982, respectively, in the first area, and $77.4 \%$ and $55.8 \%$ in 1977 and 1982, respectively, in the second area. The decline of mosquito densities had a relationship with both the wet irrigation applications and fish cultivation in the ponds and puddles.

Fish cultivation could be applied in irrigation canals and ditches of irrigation systems of rice fields. This is related to the control of An. sinensis and Cx. tritaeniorhynchus (Malaria control trail working group of Henan province, Zhoukou district and Luyi county in Guantang commune 1974b). Vegetation, such as Myriophyllum verticillatum, Potamogetom polygonifolius and Hydrilla verticillata were present in the irrigation canals and ditches, where it provided shelter for mosquito larvae and breeding. Fish feed on these types of vegetation. After about 90,000 grass carps were put into the irrigation canals of $4 \mathrm{~km}$ length and $20 \mathrm{~m}$ width, the water vegetation was removed, and the densities of mosquito larvae declined significantly when compared with the control irrigation canals without fish introduction.

Beside using the fish mentioned above for control of mosquito larvae, increasing rice yields, and providing fish for food, other kinds of fish, stone moroko (Pseudorasbora parva) and paradise fish (Macropodus ocellatus), have been tested for the control of mosquitoes in rice fields. These fish also consumed mosquito larvae. The reduction rates of mosquito larvae were $91.21 \%$ and $97.53 \%$ at day 1 and day 2 , respectively, after stone moroko was introduced into the rice field in Changzhou of Jiangsu province. The reduction rates of larval mosquito densities were $83.16 \%, 85.44 \%, 84.48 \%$, and $81.90 \%$ at $4,7,20$, and 25 days, respectively, after stone moroko was introduced into the rice field in Yancheng of Jiangsu province(Xu et al. 2019). The reduction rates of larval mosquito densities in rice field were $100 \%, 85.3 \%$, and $80.4 \%$ after release of paradise fish at the densities of $1 \mathrm{fish} / \mathrm{m}^{2}, 0.75 / \mathrm{m}^{2}$, and $0.5 / \mathrm{m}^{2}$, respectively (Zhou et al. 1993).

The rice-fish coculture system is a sustainable agricultural practice that utilizes the maximum benefit of scarce land and water resources, uses relatively fewer chemical controls, produces both carbohydrate and protein products, and conserves biodiversity (Xie et al. 2011). In addition to rice-fish coculture, several other types of rice-fishery systems are beneficial to mosquito control. Previous work investigated the use of ducks in rice fields for mosquito control in Wushe County in 1979 and Tongbai county in 1983 in Henan province. Ducks feed on larvae of mosquito in rice field and feeding behavior of dusks disturb ecological habitats of aquatic organism (including of mosquito), which is the disadvantage of survival of aquatic organism (Ge et al. 1991). Based on the collection of mosquito larvae at 10-day intervals, the reduction rates of larval populations were 92.36 and $99.02 \%$ in Wushe county in August and September, respectively. The reduction rates of $A n$. sinensis and $C x$. 
tritaeniorhynchus were $88.04 \%$ and $86.00 \%$, respectively, in Tongbai county, where ducks were released into rice fields every morning at 35 ducks $/ \mathrm{Mu}$ (0.067 ha). The rice yield increased by about $10 \%$ and the ducks were harvested (Ge et al. 1991).

\section{Azolla, Bacillus thuringiensis israelensis (Bti) and Bacillus sphaericus (Bs) for the control of mosquitoes}

Azolla belongs to Azollaceae as a kind of small fern that floats on water surface, lives in symbiosis with certain cyanobacteria including of Anabaena azollae and is cultivated in rice fields. Stocking of Azolla in rice fields was conducted in some areas of China. Coverage of Azolla on the water surface could prevent the oviposition of $C x$. tritaeniorhynchus and have no effect on the oviposition of An. sinensis, if water surface was covered completely, the oviposition of $C x$. tritaeniorhynchus was blocked based the observation on laboratory studies, it maybe that female adult of $C x$. tritaeniorhynchus need more interspace on water surface to lay eggs and form egg rafts, An. sinensis lay eggs singly and only need a little interspace on water surface for oviposition. Although Azolla do not affect the oviposition of An. sinensis, the rate of eclosion of pupae declined to $15.2 \%$ with full coverage of Azolla on the water surface (Lu et al. 1987, Lu 1988). When the coverage of Azolla filiculoides in the water surface in rice field reached $90 \%$, it reduced $79.96 \%$ of larval Cx. tritaeniorhynchus. However, this did not significantly influence the density of larval Anopheles in Guidong county of Hunan province in 1987 (Hu et al. 1989). Mosquito breeding was effectively inhibited when approximately $95 \%$ or $>95 \%$ water surface was covered with Azolla, based on collections of adults and larvae of mosquitoes in the same areas above (Zhang et al. 1991).

Several experiments with Bacillus thuringiensis israelensis (Bti) against larval mosquitoes in rice field showed successful control in several areas in China (Huang et al. 1995; Ming et al. 1998; Wang 1984; Wang et al. 2006; Xia et al. 1994; Xu et al. 1983; Zhang et al. 1995; Zhen et al. 1989). The application of $B t i$ at a rate of $1,3,5 \mathrm{ppm}$ in $360 \mathrm{Mu}(0.067 \mathrm{ha})$ rice fields was conducted five times respectively, from July to September. The reduction rate of densities of mosquito larvae were 93-99\% (Wang 1984). There was a field experiment of Bt-187, a strain isolated from Hubei province. After application of this strain in rice fields to control An. sinsesis and Cx. tritaeniorhynchus, the treatment resulted in a total of $98 \%$ reduction of the densities of both An. sinsesis and $C x$. tritaeniorhynchus at $24 \mathrm{~h}$, and $86 \%$ and $98 \%$ density reductions of An. sinsesis and Cx. tritaeniorhynchus, respectively, at $72 \mathrm{~h}$ (Xu et al. 1983). Based on larval Anopheles feeding behavior on the surface of the water, a floating granular of Bt-187 was applied into rice fields. The effectiveness of the floating granular Bt-187 against An. sinsesis larvae lasted for 16 days. The reduction rates of larval An. sinsesis were from 100 to $95.9 \%$ within 11 days after application at 0 . $81 \mathrm{~g} / \mathrm{m} 2$ of Bt-187(220ITU/mg) in a $200 \mathrm{Mu}$ (0.067 ha) rice field (Zhang et al. 1995).

There was a report that the reduction rate of total density of mosquito larvae was $89.16 \%$ after application of Bacillus sphaericus (Bs) in rice field in Wujin county in Jiangsu province (Wang 1997).

There were several successful trials to use Bti and $B s$ for control of both Anopheles and Culex mosquito larvae in China over the past many years. However, the mass application of these biocontrol agents has not been adopted into the IMM program in rice fields due to the huge amount of rice fields and high cost of application in China.

\section{Summary}

Although there are many kinds of research on mosquito breeding in rice fields, the irrigation system, and rice-fish coculture methods are practical and have been applied widely in China. These have been based on environmental conditions of rice fields and the benefits from the development of water-saving agriculture and aquaculture. Agricultural marketing and governmental promotion have played an important role. There are a couple of model constructions of ricefish cocultures in several provinces for national demonstration, education, and extension. The innovation in agriculture has facilitated and benefited mosquito control in rice fields and played an important part in the elimination of filariasis and malaria, and prevention of other mosquito-borne diseases in China. 
Author contributions Zhao and Xue are equal in formation of the concept of the manuscript, Zhao collected the literature, and wrote the manuscript, Xue revised the manuscript.

Funding No funding to the related manuscript, which is a review of literature.

Data availability Not applicable.

\section{Declarations}

Conflict of interest There are no conflicts of interest.

Consent to Participate Not applicable.

Clinical Trails Registration Not applicable.

Plant Reproduction Not applicable.

Research involving human and/or animal participants Not applicable.

Open Access This article is licensed under a Creative Commons Attribution 4.0 International License, which permits use, sharing, adaptation, distribution and reproduction in any medium or format, as long as you give appropriate credit to the original author(s) and the source, provide a link to the Creative Commons licence, and indicate if changes were made. The images or other third party material in this article are included in the article's Creative Commons licence, unless indicated otherwise in a credit line to the material. If material is not included in the article's Creative Commons licence and your intended use is not permitted by statutory regulation or exceeds the permitted use, you will need to obtain permission directly from the copyright holder. To view a copy of this licence, visit http://creativecommons.org/licenses/by/4.0/.

\section{References}

Anonymous (2020) Prosperous development report of integrated rice and fishery of China in 2019. China Fish 2020(1):16-22 (in Chinese)

Cao XB, Jiang JP, Gu GM, Zhou HY, Ding GS, Zhong SQ, Chen $\mathrm{HC}$ (2012) Effect of intermittent irrigation in paddy fields on mosquito control. Chin J Schist Control 24(1):85-87 (in Chinese)

Chen JX, Gao K (1959) The observation of rice-fish coculture for mosquito control. Chin J Zool 3(6):237-243 (in Chinese)

Chen HC, Li GY, Wu ZH, Tang J, Jiang JP, Gu GM (2012) On yield increasing mechanism and mosquito controlling of interval irrigation. China Rice 18(2):33-36 (in Chinese)

Cooperation Group of Rice Field Mosquito Control of Wushe County (1979) Field trial of water saving, yield increase and mosquito control in rice field. Henan J Prev Med 1979(4):83-86 (in Chinese)
Gao B, Feng SZ, Kang WM, Liu QH, Yu T (2000) Rotation of irrigation and drought for sustaining control malaria. J Pract Parasit Dis 8(4):162-164 (in Chinese)

Ge FX, Sun Z, Ge FC, Wen DH, An ZZ (1978) Preliminary studies on the effect of wet irrigation on paddle field for the control of breeding of mosquito larvae. Chin J Prev Med 12(1):20-22 (in Chinese)

Ge FX, Sun Z, Jiang QB, Sun YC (1981) The study on the control of mosquitoes in the paddy field by wet irrigation in the alluvial plain of the Yellow River. Acta Ecol Sin 1(2):168-176 (in Chinese)

Ge FX, Chen HL, Cheng XJ, Yan WS (1985) Integrated control of mosquitoes in paddle areas on the alluvial plain of the Yellow River. J Henan Med Coll 20(4):255-258 (in Chinese)

Ge FX, Sun Z, Liu YB, Cheng XJ (1991) Experimental studies on multiplication control of mosquito and its larvae by putting ducks out to rice field. Chin J Vector Biol Control 2(2):77-79 (in Chinese)

Harbach RE (2004) The classification of genus Anopheles (Diptera: Culicidae): a working hypothesis of phylogenetic relationships. Bull Entomol Res 94(6):537-553

Hu YF, Li HM, Gu SS, Xu RM, Lu BL (1989) Cultivation of a fern, Azolla filiculoides in rice field for mosquito control. Chin J Biol Control 5(3):104-106 (in Chinese)

Hu LL, Zhang J, Ren WZ, Guo L, Cheng YX, Li JY, Li KX, Zhu ZW, Zhang JE, Luo SM, Cheng L, Tang JJ, Chen X (2016) Can the co-cultivation of rice and fish help sustain rice production? Sci Rep 6:28728. https://doi.org/10.1038/ srep28728

Huang TS, Zong MQ (2007) Prosperous prospect of paddy field in building on new socialist countryside in China. Chin Fish Econ 3:27-29 (in Chinese)

Huang GQ, Chen GY, Ming GZ, Xu BZ (1995) Observation on the efficacy of Bacillus thurgiensis 187 floating granular against Anopheles sinensis larvae. Chin J Vector Biol Control 6(6):401-403 (in Chinese)

Li BS, Zhang JT, Liu WJ, Peng JX, Luo YG, Xu RM (1986) Effect of pisciculture on mosquito control in paddy field. Chin J Biol Control 2(3):135-137 (in Chinese)

Li DX, Peng SZ, Xu JZ, Ding JL, He Y, Yu JY (2005) Effect of water-saving irrigation on eco-environment of paddy field. J Hohai Univ (Nat Sci) 33(6):629-633 (in Chinese)

Li J, Chen J, Jiang N (2019) Status quo and development prospect of paddy field aquaculture in China. Agric Outlook 15(1):61-65 (in Chinese)

Liao S, Xu BZ, Chen CY, Liang ZP, Zhang HF (1991) Breeding grass carp against mosquito in rice field. Chin J Parasitol Parasit Dis 9(3):219-222 (in Chinese)

Liu QH, Cao CZ, Li Y, Kang WM (2002a) Doujiangyan irrigation system and malaria control effectiveness in Sichuan. J Pract Parasit Dis 10(1):13-15 (in Chinese)

Liu QH, Cao CZ, Li Y, Kang WM (2002b) Analysis on malaria control effectiveness under different control measures in Sichuan Province. J Pract Parasit Dis 10(2):49-52 (in Chinese)

Liu QH, Cao CZ, Feng SZ, Li Y, Kang WM (2002c) Efficacy of agricultural strategy of irrigation on malaria control. Abstract book of the first annual meeting of Chinese Preventive Medicine Society, p. 323 (in Chinese) 
Liu QH, Cao CZ, Wang MP, Kang WM (2003) Implementation of agricultural irrigation strategy for control of malaria in Shibantan Township of Xindu District of Chengdu City. China Trop Med 3(3):295-297 (in Chinese)

Lu BL (1978) Integrated management of mosquito. Science Press, Beijing (in Chinese)

Lu BL (1988) The effect of Azolla on mosquito breeding. Parasitol Today 4(11):328-329

Lu BL (1997a) Fauna sinica, insecta, volume 8, diptera, culicidae, vol 1. Science Press, Beijing (in Chinese)

Lu BL (1997b) Fauna sinica, insecta, volume 9, diptera, culicidae, vol 2. Science Press, Beijing (in Chinese)

Lu BL (1999) Integrated management of mosquito, 2nd edn. Science Press, Beijing (in Chinese)

Lu BL, Xu RM, Zhang JS, Ji SH (1987) Laboratory studies of the effect of Azolla sp. on mosquito breeding. Chin J Bio Control 3(4):160-162 (in Chinese)

Malaria Control Trail Working Group of Henan Province, Zhoukou District and Luyi County in Guantang Commune (1973) Observation of rice-fish coculture for mosquito control combined with the practice of agriculture and fishery. Henan J Prev Med 1973(3):24-30 (in Chinese)

Malaria Control Trail Working Group of Henan Province, Zhoukou District and Luyi County in Guantang Commune (1974a) Continuing observation on effect of rice-fish coculture for mosquito control. Henan J Prev Med 1974(1):9-14 (in Chinese)

Malaria Control Trail Working Group of Henan Province, Zhoukou District and Luyi County in Guantang Commune (1974b) Observation on raising grass carps to remove aquatic grass to control mosquito. Henan J Prev Med 1974(1):15-19 (in Chinese)

Malaria Control Trail Working Group of Nangyang County (1975) Preliminary observation on effect of rice-fish coculture for mosquito control. Henan J Prev Med 1975(2):12-16 (in Chinese)

Ming GZ, Yuan FY, Zhang JB, Xu BZ (1998) Observation on the efficacy of Bacillus thurgiensis and Bacillus sphaericus floating granular for mosquito control. Hubei J Prev Med 9(1):31-32 (in Chinese)

Ni DS, Wang JG (1981) Studies on theory of the rice-fish commensalism system. Fish Sci Technol Inf 6:1-3 (in Chinese)

Qu FY (2005) On the taxonomic status of Anopheles anthropophagus and Anopheles lesteri from China (Diptera: Culicidae). Chin J Parasitol Parasit Dis 23(4):243-245 (in Chinese)

Qu FY (2008) Historical review on the classification and rectification of Anopheles anthropophagus to A. lesteri in China. Chin J Parasitol Parasit Dis 26(3):234-235 (in Chinese)

Ren WZ, Hu LL, Guo L, Zhang J, Tang L, Zhang ET, Zhang JE, Luo SM, Tang JJ, Chen X (2018) Preservation of the genetic diversity of a local common carp in the agricultural heritage rice-fish system. Proc Natl Acad Sci USA 108(50):115(3): E546-E554

Rueda LM, Wilkerson RC, Li C (2005) Anopheles (Anopheles) lesteri Baisas and $\mathrm{Hu}$ (Diptera: Culicidae): neotype designation and description. Proc Biol Soc Wash107(3):604-622
Sun RK, Wang DK, Jia JX, Pan SD, Jiang MQ, Wang WL, Shi ZM, Xu RX, Li JB, Liu HK (1988) Studies of malaria control strategy in irrigation and drought intercropping area in north of Jiangsu province. Chin J Parasit Dis Control 1(1):9-12 (in Chinese)

Sun RK, Wang DK, Jia JX, Pan SD, Nie ZH, Wang WL, Li JB, Xu RX, Jiang MQ, Wu QZ (1989) Wet irrigation of rice field for mosquito control. Chin J Parasitol Parasit Dis 7(4):294-295 (in Chinese)

Tang JJ, Li W, Lv XT, Wang YJ, Ding XY, Jiang J, Tang YB, Li JM, Zhang JB, Du J, You Y, Li XD, Li B, Cheng YX, Dou Z, Gao H, Chen X (2020) Development status and rethinking of the integrated rice-fish system in China. China Rice 26(5):1-10 (in Chinese). https://doi.org/10. 3969/j.issn.1006-8082.2020.05.001

Wang MX (1984) New microbic insecticide: Bacillus thuringiensis var. israelensis. J Public Health Dis Control 3(2):37-40 (in Chinese)

Wang MX (1997) Studies of Bs-10 for mosquito larvae control. Chin J Hyg Insect Equip 3(3):9-14 (in Chinese)

Wang RR, Tang LH, Gu ZC, Jiang WK, Zhou SS, Huang GQ, Zhang HX (2006) Study on toxicity and efficacy of Bacillus thuringiensis var.israelensis emulsion against Anopheles anthropophagus and Anopheles sinensis in the field. J Pathog Biol 1(2):117-119 (in Chinese)

Wu N (1984) Rice-fish coculture, important approach for vector control and prevention of diseases. China Fish 1984(2):19 (in Chinese)

Xia SG, Wu KL, Yuan FY, Xu BZ (1994) Observation of efficacy of floating granular of Bti-H14 and Bs C3-41against mosquito larvae in the field. $\mathrm{J}$ Med Pest Control 10(1):15-16 (in Chinese)

Xie J, Hu LL, Tang JJ, Wu X, Li NN, Yuan YG, Yang HS, Zhang JE, Luo SM, Chen X (2011) Ecological mechanisms underlying the sustainability of the agricultural heritage rice-fish coculture system. Proc Natl Acad Sci USA 108(50):E1381-E1387

Xu BZ, Zhong T, Yuan FY, Huang GQ, Huang SQ (1983) Observation on the efficacy of Bacillus thurgiensis 187 suspending agent for mosquito control in the field trial. Public Health Dis Control 2(6):35-37 (in Chinese)

$\mathrm{Xu}$ YH, Zhang Y, Li PP (2019) Observation of efficacy raising Pseudorasbora parva in rice field for mosquito control. J Trop Dis Parasitol 17(3):172-173 (in Chinese)

Xu BH, Xu LS, Li LS, Jiang FR, Huang JY, Zhang LY, Liu DM, Sa YN, Wu JJ, Zhang SY (2002) Impact of paddy irrigation to density and dynamics of Anopheles anthropophagus. J Pract Parasit Dis 9(4):156-158 (in Chinese)

Zhang JT, Lu BL, Hu YF, Li HM, Deng CQ, Deng L, Gu DQ, Chen WY (1991) Further studies of the effect of Azolla on mosquitoes breeding in rice field. J Med Pest Control 7(3):226-229 (in Chinese)

Zhang JB, Xu BZ, Yuan FY, Ming GZ (1995) Comparison of efficacy of two kind of floating granules of B.t.i against $A n$. sinensis larvae. Chin J Vector Biol Control 6(5):334-336 (in Chinese)

Zhang HL, Zhu A, Hu X, Yao L, Fang YQ, Xia SM, Liu LJ (2018) Research progress on effects of common water saving irrigation methods in paddy field on rice yield and quality. China Rice 24(6):8-12 (in Chinese). https://doi. org/10.3969/j.issn.1006-8082.2018.06.002 
Zhen TM, Hu YX, Wang HW (1989) Field efficacy of microbial insecticides C3-41 emulsion and Vectobac G 200 granular against larvae of Anopheles sinensis. Chin J Parasit Dis Control 2(Supplement Issue):80-82 (in Chinese)

Zhou J, Guo XW, Lin F (1993) Studies on efficacy of Macropodus ocellatus for mosquito control. Hubei Agric Sci 1993(7):20-22 (in Chinese)
Publisher's Note Springer Nature remains neutral with regard to jurisdictional claims in published maps and institutional affiliations. 